\title{
A LuxR homologue of Xanthomonas oryzae pv. oryzae is required for optimal rice virulence
}

\author{
SARA FERLUGA¹, JOSEPH BIGIRIMANA², MONICA HÖFTE³ AND VITTORIO VENTURI ${ }^{1,2 *}$ \\ ${ }^{1}$ Bacteriology Group, International Centre for Genetic Engineering and Biotechnology, Area Science Park, Padriciano 99, 34012 Trieste, Italy \\ 2Plant Bacteriology Group, International Centre for Genetic Engineering \& Biotechnology, Biosafety Outstation, Via Piovega 23, 31050 Ca' Tron di Roncade, Treviso, Italy \\ ${ }^{3}$ Laboratory of Phytopathology, Faculty of Bioscience Engineering, Ghent University, Coupure Links 653, 9000 Gent, Belgium
}

\section{SUMMARY}

In Gram-negative bacteria a typical quorum sensing (QS) system usually involves the production and response to acylated homoserine lactones (AHLs). An AHL QS system is most commonly mediated by a Luxl family AHL synthase and a LuxR family AHL response regulator. This study reports for the first time the presence of a LuxR family-type regulator in Xanthomonas oryzae pv. oryzae (Xoo), which has been designated as OryR. The primary structure of OryR contains the typical signature domains of $\mathrm{AHL}$ QS LuxR family response regulators: an AHL-binding and a HTH DNA binding motif. The oryR gene is conserved among 26 Xoo strains and is also present in the genomes of close relatives $X$. campestris pv. campestris and $X$. axonopodis pv. citri. Disrupting oryR in three Xoo strains resulted in a significant reduction of rice virulence. The wild-type $X o o$ strains do not seem to produce AHLs and analysis of the Xoo sequenced genomes did not reveal the presence of a Luxl-family AHL synthase. The OryR protein was shown to be induced by macerated rice and affected the production of two secreted proteins: a cell-wall-degrading cellobiosidase and a 20-kDa protein of unknown function. By expressing and purifying OryR it was then observed that it was solubilized when grown in the presence of rice extract indicating that there could be a molecule(s) in rice which binds OryR. The role of OryR as a possible in planta induced LuxR family regulator is discussed.

\section{INTRODUCTION}

Bacteria which belong to the genus Xanthomonas are Gramnegative belonging to the Gammaproteobacteria and are significant pathogens to a large number of plants worldwide (Vandamme et al., 1996). One member of the genus is Xanthomonas oryzae pv. oryzae (Xoo), which is the causal agent of a serious disease in rice called bacterial leaf blight (Swings et al., 1990). This

\footnotetext{
*Correspondence: Tel.: 040 3757317; Fax: 040 226555; E-mail: venturi@icgeb.org
}

disease causes severe losses and is most predominantly found in tropical Asian countries. It is a vascular disease whereby Xoo continues to grow until the xylem vessels are clogged with bacterial cells and extracellular polysaccharides. In the last 15 years several studies have improved our understanding of the molecular determinants of rice/Xoo interaction with the cloning of several rice resistance $(X a)$ genes, Xoo avirulence (avr) genes and the hypersensitive response and pathogenicity $(h r p)$ genes (Leach and White, 1996; Leach et al., 2001; Shen and Ronald, 2002). Importantly, Xoo consists of a diversity of races which exhibit different virulence, thus making the breeding of durable resistant rice cultivars a major challenge. Recently, the genomes of two Xoostrains have been completely sequenced, annotated and published (Lee et al., 2005; Ochiai et al., 2005).

In most bacteria a major level of regulation involves intercellular communication via the biosynthesis and response to signal molecules (Camilli and Bassler, 2006). It is a cell-density-dependent regulation of gene expression which has been termed quorum sensing (QS) (Fuqua et al., 1994). QS provides significant advantages to a community of bacteria including improving access to environmental niches, enhancing defence capabilities against other microorganisms or eukaryotic host-defence mechanisms, and facilitating the adaptation to changing environmental conditions (for reviews see Camara et al., 2002; Fuqua and Greenberg, 2002; Waters and Bassler, 2005). In fact, it is most probable that in natural ecosystems bacteria are often aiming at establishing communities rather than choosing to exist as solitary cells. In Gram-negative bacteria, a typical QS system usually involves the production and response to an acylated homoserine lactone (AHL). The AHL-dependent QS system is commonly mediated by two proteins belonging to the LuxI-LuxR families (Fuqua and Greenberg, 2002). Luxl-type proteins are responsible for synthesizing AHLs from $S$-adenosyl methionine and particular fatty acyl carrier proteins. AHLs then interact directly, at quorum concentration, with the cognate LuxR-type protein and this protein-AHL complex can then bind at specific gene promoter sequences called lux-boxes affecting expression of QS target genes. AHL QS has been the subject of extensive investigation in recent years 
and has become a paradigm for bacterial intercellular signalling. Other QS signalling molecules have been discovered which are produced by Gram-negative bacteria, including a quinolone signal molecule produced by Pseudomonas aeruginosa and a molecule designated Al-2 (4,5-dihydroxy-2,3-pentanedione, DPD), which is produced by a wide range of bacteria (Camilli and Bassler, 2006; Waters and Bassler, 2005). In addition, it is also becoming evident that bacteria can produce and respond to more than one QS signalling molecule (Camilli and Bassler, 2006).

To our knowledge, in the genera Xanthomonas there are no reports of the presence of AHL QS systems. By contrast, QS has been reported in Xanthomonas campestris pv. campestris and Xoo to occur via a signalling molecule designated DSF (diffusible signal molecule) (Chatterjee and Sonti, 2002; Dow et al., 2003; He et al., 2006). DSF has been characterized as cis-11-methyl-2dodecenoic acid synthesized by the RpfF protein (Barber et al., 1997); DSF signalling is involved in the regulation of biofilm dispersal and production of virulence factors. Current studies support the role of a two-component regulatory system designated
RpfC/RpfG in the perception and transduction of the DSF signal to target genes (Dow et al., 2003; He et al., 2006). In the present study we investigated whether $X_{0 o}$ produces and responds to AHLs and present evidence (1) that a set of Xoo isolates do not produce AHLs, (2) for the existence of a conserved LuxR QS regulator in Xoo which we designated OryR, (3) that OryR is important for rice virulence, (4) that OryR is induced by macerated rice and (5) that OryR most probably interacts with a plant signal.

\section{RESULTS AND DISCUSSION}

\section{Rice pathogenicity tests on $X$. oryzae pv. oryzae isolates}

The pathogenicity of the $23 \mathrm{Xoo}$ isolates from India was tested on the susceptible rice line IR24 and three near-isogenic lines with known resistance genes IRBB5 (Xa5), IRBB7 (Xa7) and IRBB21 (Xa21). IR24 and IRBB7 were the most susceptible lines. They were resistant only to one of the 23 tested isolates, while IRBB5 and IRBB21 were resistant to seven and ten Xoo isolates, respectively (Table 1).

Table 1 Xanthomonas oryzae pv. oryzae strains used.

\begin{tabular}{|c|c|c|c|c|c|c|c|c|c|}
\hline \multirow[b]{2}{*}{ Isolate name } & \multirow[b]{2}{*}{ State in India } & \multirow[b]{2}{*}{ Site } & \multirow{2}{*}{$\begin{array}{l}\text { Year of } \\
\text { isolation }\end{array}$} & \multirow[b]{2}{*}{ Host cultivar } & \multicolumn{4}{|c|}{ Pathogenicity tests* } & \multirow[b]{2}{*}{ Reference } \\
\hline & & & & & IR24 & IRBB5 & IRBB7 & IRBB21 & \\
\hline XАPT.43 & Andhra Pradesh & Tada & 1.2003 & Unknown & $S$ & $S$ & $S$ & । & This study \\
\hline XAPC. 5 & Andhra Pradesh & Cudappah & 1.2003 & Unknown & $S$ & $S$ & $S$ & $\mathrm{R}$ & This study \\
\hline XAPC. 10 & Andhra Pradesh & Cudappah & 1.2003 & Unknown & $S$ & I & $S$ & $R$ & This study \\
\hline XAPC. 11 & Andhra Pradesh & Cudappah & 1.2003 & Unknown & $S$ & $S$ & $S$ & $\mathrm{R}$ & This study \\
\hline XAPC. 12 & Andhra Pradesh & Cudappah & 1.2003 & Unknown & $S$ & 1 & $S$ & । & This study \\
\hline XAPC. 13 & Andhra Pradesh & Cudappah & 1.2003 & Unknown & $S$ & $S$ & $S$ & $\mathrm{R}$ & This study \\
\hline XAPC. 14 & Andhra Pradesh & Cudappah & 1.2003 & Unknown & $S$ & $\mathrm{R}$ & $S$ & $\mathrm{R}$ & This study \\
\hline XAPC. 19 & Andhra Pradesh & Cudappah & 1.2003 & Unknown & $S$ & $S$ & $S$ & I & This study \\
\hline XAPC. 20 & Andhra Pradesh & Cudappah & 1.2003 & Unknown & $S$ & $\mathrm{R}$ & $S$ & $\mathrm{R}$ & This study \\
\hline XAPC. 23 & Andhra Pradesh & Cudappah & 1.2003 & Unknown & $S$ & $S$ & $S$ & $\mathrm{R}$ & This study \\
\hline XKK.3 & Kerala & Kannanur & 1.2003 & Jyothi & $S$ & $S$ & $S$ & I & This study \\
\hline XKK.4 & Kerala & Kannanur & 1.2003 & Jyothi & $S$ & $S$ & $S$ & $S$ & This study \\
\hline XKK:12 & Kerala & Kannanur & 1.2003 & Jyothi & $S$ & $S$ & $S$ & $S$ & This study \\
\hline XKK.16 & Kerala & Kannanur & 1.2003 & Jyothi & $S$ & $S$ & $S$ & $\mathrm{R}$ & This study \\
\hline XKPt.4 & Kerala & Palghat & 1.2003 & ADT.46 & $S$ & I & $S$ & $S$ & This study \\
\hline XKPt.8 & Kerala & Palghat & 1.2003 & ADT.46 & $S$ & I & $S$ & $S$ & This study \\
\hline XKP2.2 & Kerala & Parali & 1.2002 & Matta Tiruvani & $S$ & $\mathrm{R}$ & I & $\mathrm{R}$ & This study \\
\hline XP4.2 & Kerala & Pattambi & 9.1999 & Jyothi & $S$ & I & $S$ & $S$ & This study \\
\hline XKV.5 & Kerala & Valancheri & 1.2003 & Thiruveni & $S$ & $\mathrm{R}$ & $S$ & $S$ & This study \\
\hline XKV.9 & Kerala & Valancheri & 1.2003 & Thiruveni & $S$ & $R$ & $S$ & $S$ & This study \\
\hline XKV.15 & Kerala & Valancheri & 1.2003 & Thiruveni & $R$ & $\mathrm{R}$ & $R$ & $R$ & This study \\
\hline XTNAi.18 & Tamilnadu & Adthurai & 1.2003 & ADT.46 & $S$ & $\mathrm{R}$ & । & $S$ & This study \\
\hline XTNP.4 & Tamilnadu & Podi & 10.2002 & ADT.46 & $S$ & $S$ & $S$ & $S$ & This study \\
\hline LMG5047 & Unknown & Unknown & 1965 & Unknown & $S$ & $\mathrm{~N} / \mathrm{A}$ & $\mathrm{N} / \mathrm{A}$ & $N / A$ & \\
\hline $\mathrm{B} \times 043$ & Unknown & Unknown & Unknown & Unknown & $S$ & $N / A$ & $\mathrm{~N} / \mathrm{A}$ & $N / A$ & (Goel et al., 2002) \\
\hline KACC10331 & Korea† & Unknown & Unknown & Unknown & $S$ & $\mathrm{~N} / \mathrm{A}$ & $\mathrm{N} / \mathrm{A}$ & $S$ & (Lee et al., 2005) \\
\hline
\end{tabular}

${ }^{*} R$; resistant, I; intermediate, S; susceptible. See text for details.

†This strain has been isolated in Korea (Lee et al., 2005) and not in India (see text for details).

$\mathrm{N} / \mathrm{A}$, not available. 
Even though the number of tested isolates was relatively low, our results suggested that the resistance gene $\mathrm{Xa} 7$ is less efficient than Xa5 and Xa21 in the concerned sites of India. However, the adult resistance earlier demonstrated in the rice- $X o o$ interaction (Qi and Mew, 1985; Sidhu and Khush, 1978) could have influenced our results and this resistance gene was possibly not expressed in 45 -day-old rice plants. We believe that the group of 23 isolates tested is a good representation of Xoo strains, which can be used for analysis of AHL production (see below).

\section{$X$. oryzae pv. oryzae rice pathogenic bacteria do not produce AHLs}

Using bacterial biosensor AHL detector strains described in the Experimental Procedures section, all the Xoo isolates listed in Table 1 were used initially to test by growth in solid media in a plate streak assay for AHL production (Hwang et al., 1994). The bacterial biosensor Chromobacterium violaceum CVO26 induces the production of violacein when certain $\mathrm{AHL}$ signal molecules are present, Escherichia coli (pSB401) and E. coli (pSB1075) induce bioluminescence, and Agrobacterium tumefaciens NT1 (pZLR4) and Pseudomonas fluorescens 1855 (pSF105, pSF107) induce $\beta$-galactosidase production. These four AHL biosensor strains ensure that a wide range of AHLs are detected as each displays specificity towards structurally different AHLs (Steindler and Venturi, 2007). In addition to the 24 Xoo strains described above we also tested the well-studied Xoo strain BXO43 and strain KACC10331, the genome of which has been sequenced (all listed in Table 1). All 26 Xoo strains gave a negative result in solid media in plate streak assays. Although this may mean that these strains do not produce AHLs at all, we could not exclude that they did so in very low amounts. In order to test this, $100 \mathrm{~mL}$ spent culture supernatant was extracted and analysed for AHLs by thin-layer chromatography (TLC) followed by a bioassay. The detection of AHLs in TLC plates was visualized by making use of E. coli JM109 (pSB401), E. coli (pSB1075) and A. tumefaciens NT1 (pZLR4) detector strains. Again all 26 Xoo strains were tested for presence of AHLs of spent supernatant and all gave a negative result. It was concluded that Xoo most probably does not produce AHL molecules. It cannot be excluded that Xoo could be producing AHLs at extremely low amounts that cannot be detected or the AHL biosensors used here do not respond to the AHL molecules potentially produced by $X o o$.

\section{The genome of $X$. oryzae pv. oryzae contains a potential QS orphan LuxR-family member}

The genome sequences of two Xoo strains, designated as KACC10331 and MAFF311018, have been recently published (Lee et al., 2005; Ochiai et al., 2005) and a third strain, PX086, is currently being sequenced. Analysis of the genomes did not reveal any gene and/or protein which belongs to the Luxl family of AHL synthases (Fuqua and Greenberg, 2002). A second distinct, although small, family of AHL synthases has been reported and is composed of the LuxM, AinS and VanM proteins from Vibrio harvey, $V$. fischeri and $V$. anguillarum, respectively (Milton et al., 2001). Analysing the genomes of $X o o$ again revealed that no LuxM homologue was found. These results are in accordance with our observation that no AHLs could be detected from 26 different $X_{0 o}$ isolates including strain KACC10331, the genome sequence of which was available.

Analysing the three Xoo genome sequences, however, revealed the presence of a shared identical LuXR family member (Xoo KACC10331; Q5H3E9, Xoo MAFF311018; Q2P6A5 and from Xoo PX086; Q6R756), which we designated here as OryR, having the characteristic signatures of an AHL-dependent response regulator. OryR is 254 amino acids long and it contains an autoinducer binding domain (Pfam03472) from position 22 to 178 and HTH domain from 189 to 246 with the conserved region of LuxR family regulators (Fig. 1). Interestingly, although its function is unknown, an open reading frame (ORF) highly similar (over 90\%) to OryR is

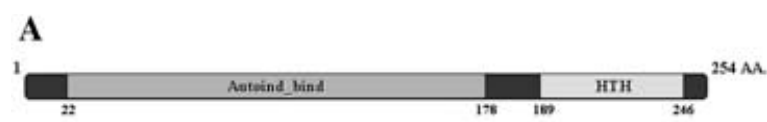

B

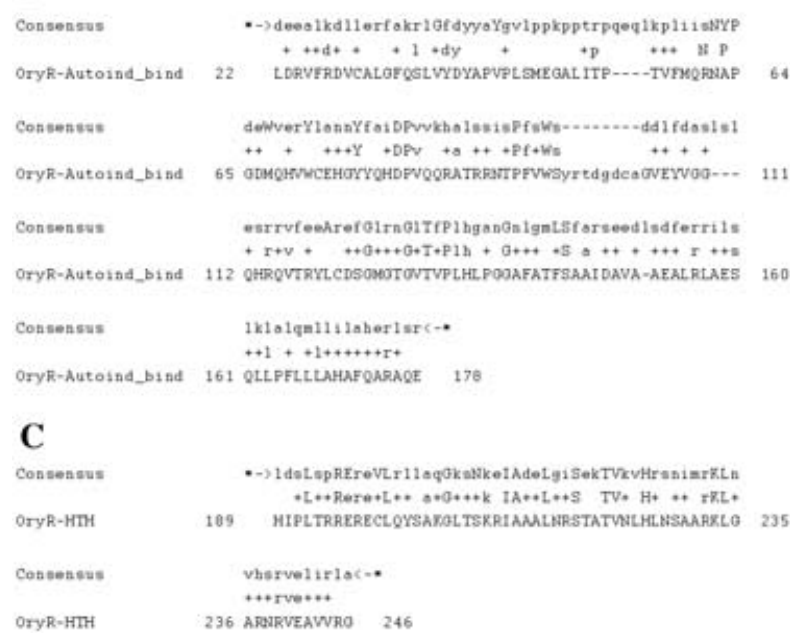

Fig. 1 The OryR protein primary structure contains domains typical of quorum sensing LuxR family regulators. (A) Schematic representation of OryR; numbers refer to amino acid residues. Positions of the AHL-binding and the HTH-DNAbinding domains are shown. (B) Alignment using the one-letter code between the consensus of the AHL binding domain (shown as consensus, Pfam03472) and (C) HTH-DNA-binding domain of LuxR family regulators and the corresponding domain in OryR. Amino acid identities of less important residues in the domains are shown as small capitals; a + sign refers to conserved amino acids with similar properties (http://www.sanger.ac.uk/Software/Pfam/). 
also present in the closely related Xanthomonas campestris pv. vesicatoria (Q3BQU7), $X$. axonopodis pv. citri (Q8P1B0) and $X$. campestris pv. campestris (Q4UX59). All ory R genes have been annotated as single transcriptional units and not part of operons. OryR displays approximately $50 \%$ similarity to several LuxR family proteins of various Pseudomonas syringae plant pathogenic species (Q48E34, Q0EE63, Q87WEEK7 and Q4ZNM6) and to several LuxR proteins belonging to members of the Rhizobium genera (Q92M411, Q1 M918 and Q2K5W3. Interestingly, all these bacteria are closely associated with plants.

OryR could therefore act as a LuxR 'orphan' (i.e. lacking a cognate Luxl AHL synthase) QS type protein possibly responding and regulating target genes to signals from neighbouring AHLproducing bacteria. Such examples have thus far not been commonly reported in bacteria; to our knowledge the only example is SdiA of E. coli and Salmonella enterica, which enables these bacteria, which do not synthesize AHLs, nevertheless to respond to exogenous AHLs produced by other bacterial species (Ahmer, 2004). Two other examples of orphan LuxR proteins have been reported which, in apparent contrast to OryR, respond to AHLs produced by the same cell. These proteins are QscR of $P$. aeruginosa and ExpR of Sinorhizobium meliloti. One proposed role of these proteins is to extend the AHL QS regulation in these bacteria to other gene targets. However, as QscR and ExpR possess a broader, more relaxed, response to a larger number of different AHLs, a second proposed role is to increase the range of AHLs to which these species respond (Hoang et al., 2004; Lequette et al., 2006).

\section{oryR is conserved in X. oryzae pv. oryzae}

As mentioned above, orthologues of ory $R$ are present in $X$. campestris pv. campestris and $X$. axonopodis pv. citri. In order to determine if ory $R$ is conserved in other Xoo isolates, we performed Southern blot analyses of Ncol restriction enzyme-digested chromosomal DNA of all 26 Xoo isolates reported in Table 1 with a DNA fragment containing the complete ory $R$ gene. This probe gave a positive hybridization signal at high hybridization stringency conditions with 19 of the 26 Xoo isolates (Fig. 2). Of the seven which did not give a signal, we analysed by Western analysis whether they contained an OryR-like protein; five of the seven did respond to anti-OryR antibody having a protein band of the expected size (data not shown). It was concluded that ory $R$ is widely and not completely conserved within the Xoo species.

\section{oryR mutants of $X$. oryzae pv. oryzae are less virulent in rice}

The ory $R$ gene has been mutated in three $X o o$ strains in order to understand its role in rice pathogenicity. The three $X_{0 o}$ strains were KACC10331, the genome of which has been sequenced, Xoo strain BX043, in which several molecular studies have been

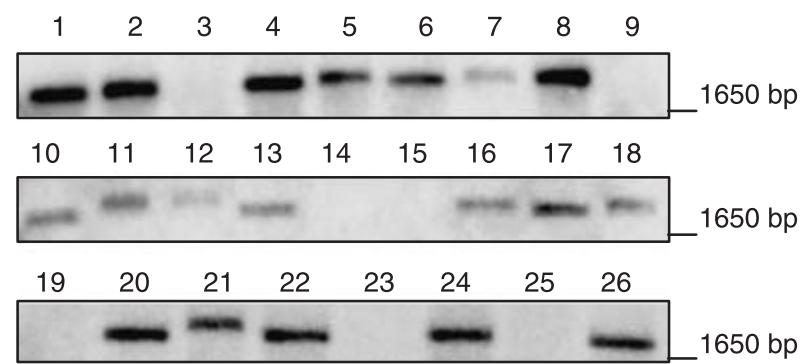

Fig. 2 High stringency Southern analysis using oryR DNA as a probe against Ncol-digested chromosomal DNA from 26 Xoo strains. The number correspond to the following Xoo strains (see Table 1 for further details): 1, XAPT.43; 2 , XAPC. 5; 3, XAPC. 10; 4, XAPC.11; 5, XAPC. 12; 6, XAPC. 13; 7, XAPC. 14; 8 , XAPC. 19; 9, XAPC. 20; 10, XAPC.23; 11, XKK.3; 12, XKK.4; 13, XKK.12; 14, XKK.16; 15, XKPt.4; 16, XKPt.8; 17, XKP2.2; 18, XP4.2; 19, XKV.5; 20, XKV.9; 21, XKV.15; 22, XTNAi.18; 23, XTNP.4; 24, LMG5047; 25, BX043; 26, KACC10331.

performed, and Xoo strain XKK.12, which has been reported here and is very virulent to rice (Table 1). Rice virulence analysis was performed with the three ory $R$ mutants as well as their respective wild-type parent strains. The assays were performed on rice leaves at very high concentration of inoculum $\left(10^{9} \mathrm{CFU} / \mathrm{mL}\right)$ as well as at lower concentration $\left(10^{8}\right.$ and $\left.10^{7} \mathrm{CFU} / \mathrm{mL}\right)$. As depicted in Fig. 3, the XKK.12 ory R mutants were less virulent as compared with the wild-type strain at all inoculum concentrations, indicating that OryR was necessary for optimal Xoo rice pathogenicity. In strains BX043 and KACC10331, however, oryR mutants displayed less virulence only at high inoculum as under these conditions the wild-type strains displayed strong virulence.

\section{OryR is solubilized by macerated rice}

The study of LuxR family QS proteins has shown that when over-expressed they are insoluble; however, in the presence of their cognate AHL molecule, which they bind with high affinity, they become soluble. In fact, the cognate $\mathrm{AHL}$ is required for the proper folding of the nascent protein, for formation of homomultimers and for protection to proteases (Chai and Winans, 2004; Collins et al., 2005; Schuster et al., 2004; Urbanowski et al., 2004; Zhu and Winans, 2001). In order to determine if the OryR protein did interact with AHLs we performed biochemical studies on the protein. By over-expressing and purifying OryR, it was established that, like other LuxR-homologue proteins, OryR was highly insoluble when overproduced in $E$. coli.

As OryR contains an Autoind_bind domain (Pfam03472, see above) it was hypothesized that if OryR was able to bind to one or more AHLs this could possibly allow OryR to solubilze. $\mathrm{His}_{6}{ }^{-}$ OryR was therefore expressed and purified in its native form in the presence of $20 \mu \mathrm{m}$ of each of several non-substituted AHLs 
(A)

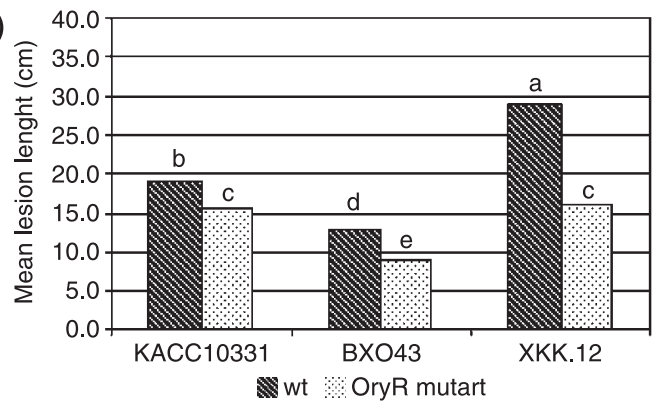

(B)

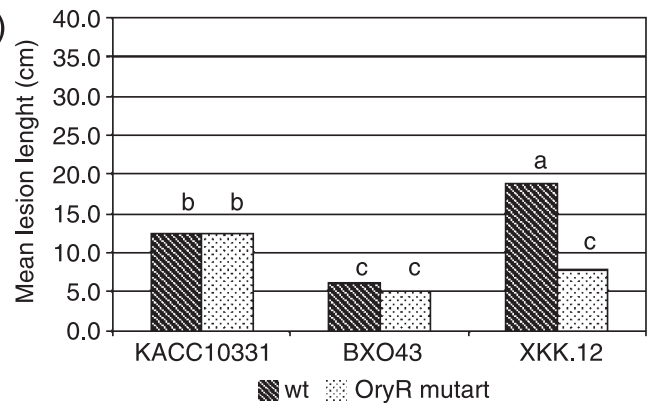

(C)

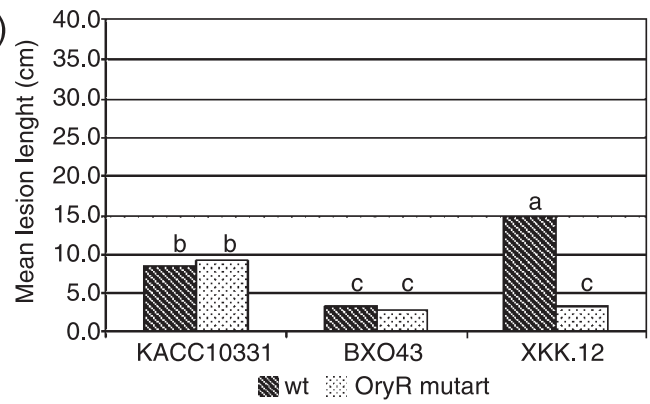

Fig. 3 oryR mutations affect Xoo virulence. Results of leaf lesion lengths caused by three $X_{0 o}$ and oryR mutant derivatives. Bars with different letters are significantly different using the Mann-Whitney comparison test performed on lesion length data. (A) A $10^{9} \mathrm{CFU} / \mathrm{mL}$ Xoo inoculum was used, (B) $10^{8} \mathrm{CFU} / \mathrm{mL}$, (C) $10^{7} \mathrm{CFU} / \mathrm{mL}$. See text for details.

(i.e. C4-, C6-, C8-, C10- and C12-AHL), several 3-oxo-AHLs (i.e. 3oxo-C6-, 3-oxo-C8-, 3-oxo-C10- and 3-oxo-C12-AHLs) and several 3-OH-AHL molecules (i.e. 3-OH-C6, 3-OH-C8, 3-OH-C10 and $3-\mathrm{OH}-\mathrm{C} 12)$. No OryR protein solubilization was observed when the protein was over-expressed in the presence of these molecules (data not shown). Although the AHLs used here are the ones most commonly used in bacteria, the list is not complete, as other structural AHLs have been reported to be produced by Gram-negative bacteria.

OryR protein solubility was also studied in the presence of plant components in the growth medium. Ten grams of rice plants (leaves and stems) were frozen with liquid nitrogen and macerated; the resultant rice powder was added to LB medium. After nickel affinity chromatography, pure His-tagged OryR in native form was eluted at $135 \mathrm{~mm}$ of imidazole (Fig. 4B). The presence of OryR in the elution peak was confirmed by Western blot analysis using
OryR antibody (Fig. 4C). As control, no OryR solubilization peak was observed in the presence of LB medium alone (Fig. 4A) or LB medium supplemented with tobacco (Xoo non-host plant) macerated powder (Fig. 4B); for both of these controls, no OryR was detected in a Western analysis of soluble fractions (data not shown). This result raises the hypothesis that molecule(s) specifically present in rice may possibly bind and solubilize some OryR. This could also be an indication that OryR might be active and performing gene regulation functions in planta (see below).

\section{OryR is induced by macerated rice}

In order to determine if OryR is expressed when Xoo KACC10331 was grown in laboratory media, we determined OryR levels using anti-OryR antibodies. When Xoo KACC10331 was grown in minimal media no OryR protein was detected with Western analysis (Fig. 5A), whereas when grown in minimal media supplemented with macerated rice, OryR levels increased significantly and could be clearly detected (Fig. 5A). These results indicate that ory $R$ is most probably induced in planta, thus most probably affecting target gene expression when $\mathrm{Xoo}$ is in rice. OryR was not detected when Xoo KACC10331 was grown in minimal media in the presence of a cocktail of exogenously provided AHLs (Fig. 5A), indicating that they do not affect the expression of oryR. It cannot be excluded, however, that some component(s) of rice extracts from macerated rice are involved in stabilizing OryR from proteolytic degradation, thus increasing protein levels rather than affecting its transcriptional status.

In order to identify possible OryR target genes, we analysed the profile of secreted proteins of the wild-type Xoo KACC10331 strain vs. the profile of the ory $R$ mutant KACC103310RYR to determine if any secreted proteins were regulated by OryR. As depicted in Fig. 5B, in KACC103310RYR two secreted proteins of approximately 60 and $20 \mathrm{kDa}$ were present at lower levels when compared with the parent strain, indicating that OryR as well as rice extract was important for their production. The approximately 60-kDa protein was digested with trypsin and analysed by mass spectroscopy, resulting in the determination of the following peptides: MGNGIDAVR, SYPTYVWLDSIDAIYGGSR, QAGLQR, TEYIDVIASTLANPKYK and FLIDTGR. Performing a BLAST analysis the peptides were $100 \%$ identical to parts of secreted enzyme 1,4-beta-cellobiosidase of Xoo KACC10331 (NC_006834.1). This secreted enzyme designated CbsA is a cell-wall-degrading enzyme, which was recently determined to be very important for Xoo virulence (Jha et al., 2007). The 20-kDa protein band was identified in a similar way with the following peptides, ADASSPINLLSPAARK, FVESLRFNASGVTSFR, IRVDSEEDR and VDSEEDR, and corresponded to a $X_{00} 20-\mathrm{kDa}$ hypothetical protein of unknown function (YP_452683). In the putative promoter regions of these two genes, we were able to identify poor potential lux-box sequences (the 1,4-beta-cellobiosidase gene contains a putative lux box at 
A

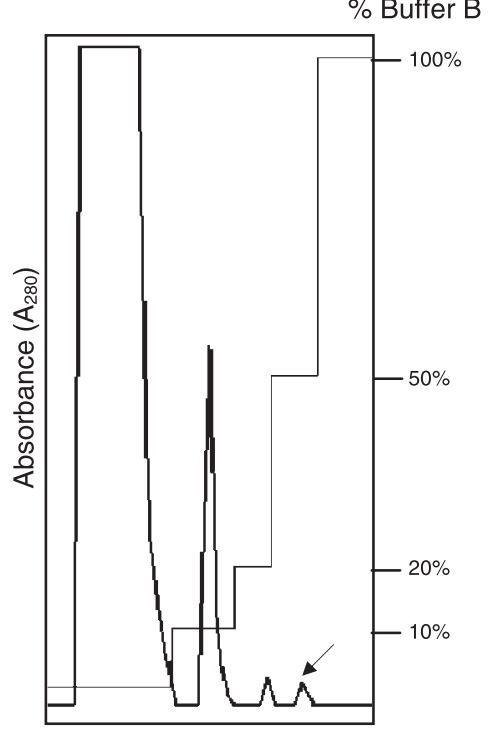

B

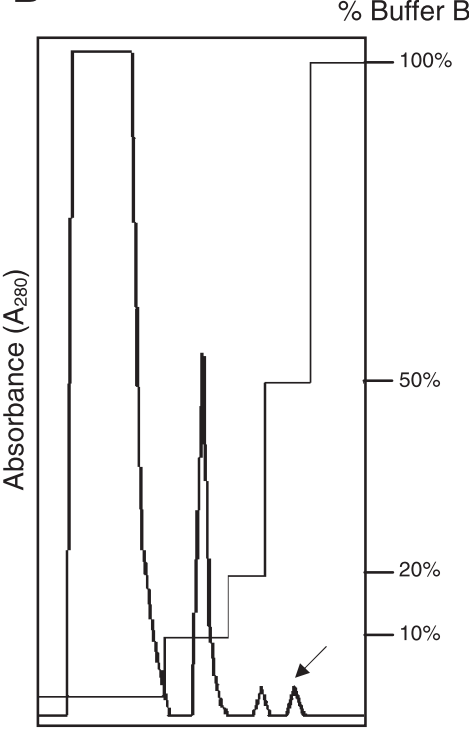

C

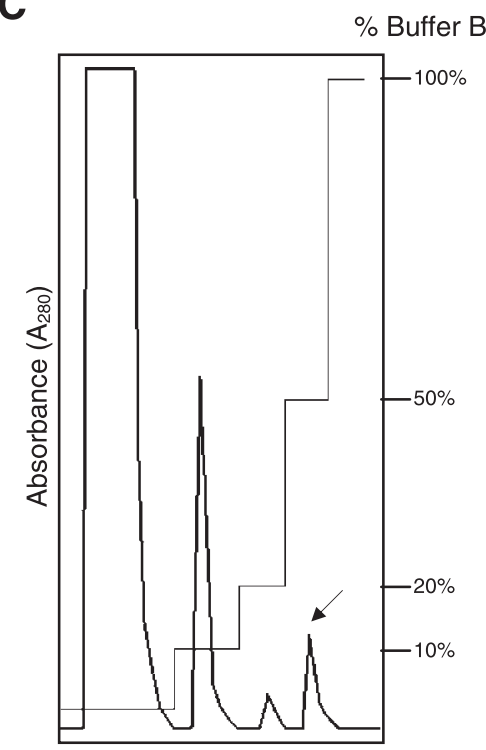

D

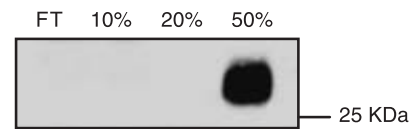

Fig. 4 Solubility studies of His6-OryR. (A) Affinity chromatography using LB as growth medium for E. coli harbouring pPQEORYR and pREP-4. Arrow indicates putative low amounts of OryR protein eluted at $50 \%$ of buffer $B$, corresponding to $135 \mathrm{~mm}$ of imidazole (see Experimental Procedures) or background due to $E$. coli His-rich proteins. (B) Affinity chromatography using LB supplemented with macerated tobacco as growth medium for $E$. coli harbouring PPQEORYR and pREP-4. Arrow indicates putative low amounts of OryR protein eluted at $50 \%$ of buffer $B$, corresponding to $135 \mathrm{~mm}$ of imidazole. (C) Affinity chromatography using LB supplemented with macerated rice as growth medium for E. coli harbouring PPQEORYR and pREP-4. Arrow indicates increase of OryR protein eluted at $50 \%$ of buffer B, corresponding to $135 \mathrm{~mm}$ of imidazole (see Experimental Procedures). (D) Western blot analysis of each elution peak from His6-OryR affinity chromatography (C) using anti-OryR antibody. The same result was obtained using Anti 6x-His monoclonal antibody (data not shown). FT, flow through.

position -411 to -430 relative to the translational start codon, whereas the 20-kDa protein is at position -205 to -221 ). Whereas, the putative promoter region of the ory $R$ gene also contains a more conserved lux-box (at position -123 to -142 ; Fig. 6). At present, however, it is not known if any of these are functional. Lux boxes in gene promoters are binding sites for LuxR family proteins (Fuqua and Greenberg, 2002).

\section{CONCLUDING REMARKS}

This study reports for the first time the presence of a LuxR familytype regulator in Xoo which has been designated as OryR. The primary structure of OryR is very similar to that of domains found in AHL-responsive QS LuxR family response regulators: an AHLbinding and a HTH DNA binding motif. We have tested 26 Xoo strains for production of AHLs and found that none produces these signal molecules. The oryR gene is conserved among Xoo strains and is also present in close relatives $X$. campestris pv. campestris and $X$. axonopodis pv. citri. Our results show that OryR is involved in rice virulence given that three $X o o$ ory $R$ mutant strains showed reduced pathogenicity. As OryR does not have a typical cognate AHL Luxl family synthase it could be defined as an orphan QS LuxR-type response regulator (Ahmer, 2004; Fuqua, 2006; Hoang et al., 2004; Lequette et al., 2006; Walters and Sperandio, 2006). Our working model is therefore centred towards the possibility that OryR responds to AHL compounds produced by other bacteria or by AHL mimic compounds derived from rice (Degrassi et al., 2007). Although attempts to solubilize recombinant OryR using several different AHL compounds failed, OryR solubilization was achieved in the presence of rice extract. This suggests that OryR could respond to some molecule(s) present in rice, indicating that this regulator could be involved in inter-kingdom signalling (Shiner et al., 2005). As OryR contains an AHL-binding motif it is reasonable to speculate that the molecule could be closely related to AHLs. Interestingly, OryR was present only when Xoo was grown in the presence of macerated rice and affected the production of two secreted proteins: a cellwall-degrading enzyme and a protein of unknown function. AHL 
(A)

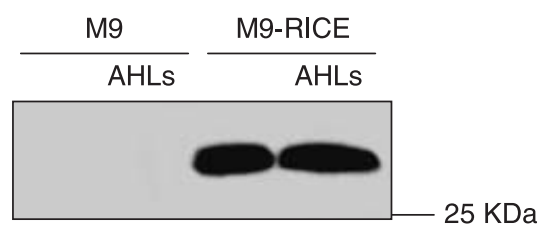

(B)

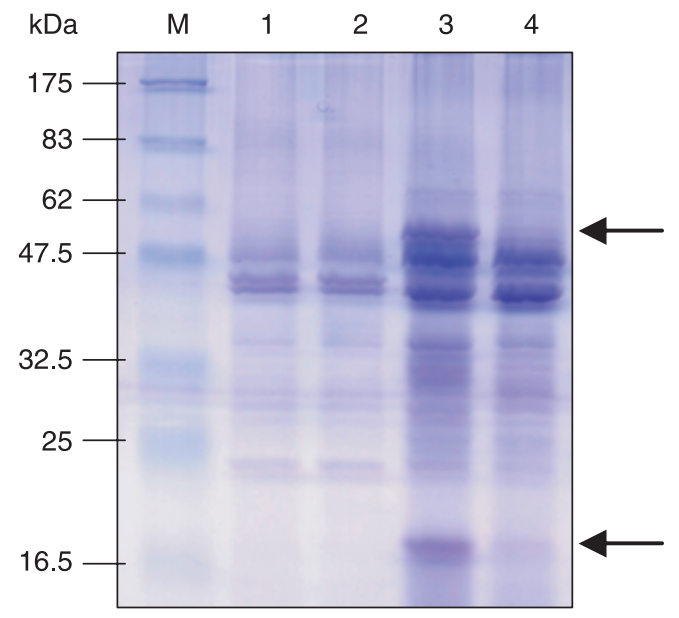

Fig. 5 (A) OryR levels in Xoo grown in different conditions. Similar amounts of stationary phase Xoo cells grown in (1) M9 medium alone or with a cocktail of AHLs (C4-, C6-, C8-, C10- and C12-AHLS, same for 3-oxo-AHLs and for 3-OH-AHLs, all added at $1 \mu \mathrm{m}$ ) and (2) M9 in the presence of macerated rice or with a cocktail of AHLs (see above). Proteins were then examined by Western analysis with anti-OryR antiserum. See text for details. (B) SDS-PAGE analysis of total secreted proteins of Xoo KACC10331 grown in minimal M9 medium (lane 1), Xoo KACC 103310RYR grown in minimal M9 medium (lane 2), Xoo KACC10331 grown in minimal M9 medium supplemented with macerated rice (lane 3) and Xoo KACC103310RYR grown in minimal M9 medium supplemented macerated rice. The arrows indicate the two proteins only seen to be produced by the wild-type KACC10331 strain grown in the presence of macerated rice and not by the ory $R$ mutant derivative.
QS is the paradigm of intercellular signalling in Gram-negative bacteria and OryR could possibly extend these systems to having roles in communication with eukaryotes. Future studies will focus on identifying Xoo gene targets of OryR and the molecule(s) to which it responds.

\section{EXPERIMENTAL PROCEDURES}

\section{Bacterial strains media and plasmids}

Xanthomonas oryzae pv. oryzae (Xoo) strains used are listed in Table 1. Detection of AHL signal molecules was performed using the following bacterial biosensors; Chromobacterium violaceum CV026, Escherichia coli JM109 (pSB401), E. coli JM109 (pSB1075), Agrobacterium tumefaciens NT1 (pZLR4) and Pseudomonas fluorescens 1855 (pSF105, pSF107) (all reviewed by Steindler and Venturi, 2007). Xoo strains were routinely grown at $28^{\circ} \mathrm{C}$ grown either in PYS (per litre: $8 \mathrm{~g}$ peptone, $2 \mathrm{~g}$ yeast extract, $2 \mathrm{~g} \mathrm{~K}_{2} \mathrm{HPO}_{4}$ $0.5 \mathrm{~g} \mathrm{KH}_{2} \mathrm{PO}_{4}, 0.25 \mathrm{~g} \mathrm{MgSO}_{4} \cdot 7 \mathrm{H}_{2} \mathrm{O}, 10 \%$ glucose w/v) PS medium (Tsuchiya et al., 1982) or in M9 minimal medium with the addition of Casamino acids (Sambrook et al., 1989) and if necessary macerated cv. Baldo rice plants (rice plants were frozen at $-80{ }^{\circ} \mathrm{C}$, then macerated with a pestle and mortar). Kanamycin at $100 \mu \mathrm{g} / \mathrm{mL}$ was used for Xoo growth. E. coli was routinely grown in LB medium at $37{ }^{\circ} \mathrm{C}$ and antibiotics were added when necessary at the following concentrations: ampicillin, $100 \mu \mathrm{g} / \mathrm{mL}$; kanamycin, $100 \mu \mathrm{g} / \mathrm{mL}$; tetracycline, $15 \mu \mathrm{g} / \mathrm{mL}$.

\section{Recombinant DNA techniques}

Digestion with restriction enzymes, agarose gel electrophoresis, purification of DNA fragments, ligation with T4 DNA ligase, end filling with Klenow fragment of DNA polymerase, Southern hybridization and transformation of E. coli were performed as described (Sambrook et al., 1989) Analytical amounts of plasmids

\section{A}

$$
\begin{aligned}
& \text { GAAAGGGATGCCGACGCGCAGCGCAGATGCTGAAGGG } \\
& -142 \quad-123 \\
& \text { ACCTGAACGCCCGTTCTGCGCTGCAGTCATGTGACCG }
\end{aligned}
$$$$
\text { GCATTGTGCCGATAATGTGGCCCACACACCCATCCAT }
$$$$
\text { TGGCAAAAGTGCTAGGTTTTCCCTGCTGGTTGTCGCT }
$$

B

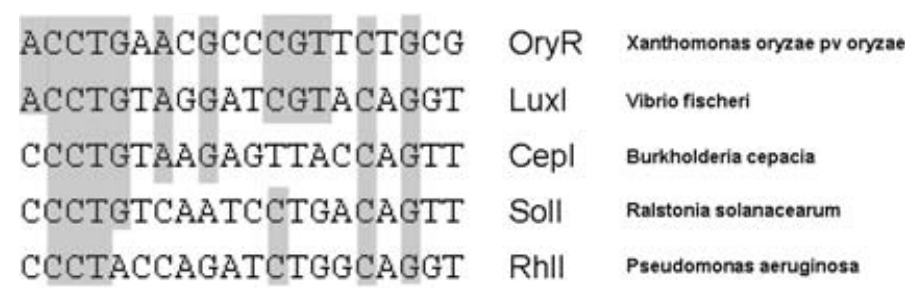

$$
\text { TGTGGGCAACCACCGGTACCGAGGAATCACCATGTTC }
$$

Fig. 6 Putative lux box in the oryR promoter region. (A) Nucleotide sequence of the promoter region of the oryR gene; underlined is the RBS (putative Shine Dalgarno sequence) and the ATG of the translational start codon. Boxed is the putative lux box and the numbers indicate the distance relative to the start codon. (B) Alignment of the oryR putative lux box with lux boxes in the promoter of the AHL synthases of several bacteria. Shaded are the conserved nucleotides. 
were isolated as described (Birnboim, 1983), whereas preparative amounts were purified with Qiagen columns. Total DNA from Xoo was isolated by the sarcosyl-pronase lysis method (Better et al., 1983).

\section{Purification, detection and visualization of signal (AHL) molecules}

The purification, detection and visualization of AHL signal molecules from culture supernatants were performed essentially as previously described (Steindler and Venturi, 2007, and references therein). Synthetic C4-AHL to C12-AHL were purchased from Fluka Chemie AG (Buchs, Switzerland) and C6-30xo-AHL to C123-oxo-AHL and C6-3-OH-AHL to C12-3-OH-AHLs were purchased from the laboratory of Professor Paul Williams (University of Nottingham, UK).

\section{Inactivation of oryR of $X$. oryzae pv. oryzae}

The Xoo KACC10331 oryR gene was in part amplified by PCR as a 385-bp fragment using primers oryRintS, 5'-CGTCTAGAGGTGGAATATGTGG-3', and oryRintR, 5' ${ }^{\prime}$-ATCTCTGAGTTCAGATGCAGGT-3', and cloned as an Xbal-Xhol fragment in pKNOCK-Km (Alexeyev, 1999) generating pKNORY. This latter plasmid was used as a suicide delivery system in order to create an oryR knock-out mutant in Xoo strains KACC10331, BXO43 and XKK.12 as described (Alexeyev, 1999) generating KACC103310RYR, BX043ORYR and XKK.120RYR. The fidelity of the marker exchange events was confirmed by Southern analysis (data not shown).

\section{OryR antibodies and protein analysis}

Antibodies against OryR of Xoo were generated by injecting purified protein into rabbits. Xoo OryR was purified as $\mathrm{His}_{6}$-OryR in PQEORYR in E. coli M15 (pREP-4) according to the instructions of the supplier (Qiagen, Hilden, Germany). pQEORYR was constructed as follows: oryR of Xoo KACC10331 was amplified by PCR using two oligonucleotides, oryRqes, $5^{\prime}$-CCCGGATCCTTCGAAATTCTA-3', and oryRqer, 5'-ACCAAGCTTTTATGGCTCCAG-3', and cloned as a BamHI-Hindlll fragment in PQE30 (Qiagen) yielding PQEORYR.

Proteins were transferred on to PVDF membrane (Immobilon$P$; Millipore) using a tank system according to the manufacturer's instruction. The membrane was subjected to Western blot analysis using polyclonal antibodies against either OryR or $6 \mathrm{x}$-His monoclonal antibody (BD Biosciences, San Jose, CA) and after incubation with the second HRP-labelled antibody the proteins were detected with the 3-3'-diaminobenzidine (DAB) tetrahydrochloride tablets (Sigma, St. Louis, MO). No significant cross-reaction of the polyclonal antibody against other Xoo or E. coli proteins was observed in this study.
Total secreted proteins were isolated and characterized as follows. Cells from $10-\mathrm{mL}$ overnight cultures were pelleted by centrifugation for $10 \mathrm{~min}$ at $8000 \mathrm{~g}$. Cells remaining in the supernatant were removed by an additional centrifugation step for $3 \mathrm{~min}$ at $15000 \mathrm{~g}$. Proteins in the cell-free supernatant were then precipitated with $10 \%(\mathrm{w} / \mathrm{v})$ trichloroacetic acid, dried and resuspended in $40 \mu \mathrm{L}$ of sample buffer and loaded at $20 \mu \mathrm{L}$ in the SDS-PAGE gel.

Protein analysis of secreted and total proteins was performed by boiling the protein suspension in sample buffer for $10 \mathrm{~min}$; the proteins were then separated by sodium dodecyl sulphatepolyacrylamide gel electrophoresis (SDS-PAGE) on gels containing $12 \%(\mathrm{w} / \mathrm{v})$ polyacrylamide.

Selected protein bands were identified as follows: the band was cut out from the Coomassie Brilliant blue-stained gel and placed in a siliconized microcentrifuge tubes that had been rinsed with water and ethanol. The band was digested with trypsin, and the resulting peptides were extracted with water and $60 \%$ acetonitrile/ $1 \%$ trifluoroacetic acid. The fragments were then analysed by mass spectroscopy (an internal sequence analysis of the protein spots was performed by using an electronspray ionization mass spectrometer LCQ DECA XP, ThermoFinnigam); proteins were identified by analysis of the peptides and by using the $X_{0 o}$ protein data banks.

\section{OryR over-expression and purification}

For OryR over-expression, a single plate colony of E. coli M15PQEORYR was used to inoculate $10 \mathrm{~mL}$ of LB-ampicillin-kanamycin and grown overnight; $1 \mathrm{~mL}$ of the culture was then used to inoculate $100 \mathrm{~mL}$ of prewarmed medium. Expression was induced adding $1 \mathrm{~mm}$ isopropyl- $\beta$-D-thiogalactoside at an $\mathrm{OD}_{600}$ of 0.6 and carried on for $3 \mathrm{~h}$ at $37^{\circ} \mathrm{C}$. The culture was rapidly chilled on ice and the cells were harvested by centrifugation and frozen at $-80^{\circ} \mathrm{C}$.

$\mathrm{His}_{6}$-OryR protein was extracted under denaturing and native conditions according to the supplier's instructions (Quiagen). The purification step was performed using a 5-mL HiTrap affinity column (Amersham Pharmacia). Native $\mathrm{His}_{6}{ }_{-}$OryR was eluted using a imidazole step gradient [10 mm (Buffer A) and $250 \mathrm{~mm}$ (Buffer B)]. Protein concentration was determined by using a Bradford assay (Bio-Rad).

\section{Bacterial leaf blight virulence assays on rice plants}

Xanthomonas oryzae pv. oryzae isolates were grown on Sucrose Peptone Agar medium (Tsuchiya et al., 1982) at $28^{\circ} \mathrm{C}$ and single colonies were transferred to liquid Sucrose Peptone medium. Two-day-old cultures were used for inoculum production. The bacterial concentration was determined using a spectrophotometer (Multiscan Ex) and adjusted to $10^{9}, 10^{8}$ or $10^{7} \mathrm{CFU} / \mathrm{mL}$ with demineralized water. Pathogenicity tests on the Xoo strains in Table 1 
were carried out on rice cultivar IR24 and three NILs (Near Isogenic Lines): IRBB5, IRBB7 and IRBB21 (from the International Rice Research Institute). Germinated rice seeds were grown in trays in a potting compost (Klassmann substrate 4, Geeste, Germany) under greenhouse conditions $\left(30 \pm 4^{\circ} \mathrm{C}\right)$ with a 16 : 8-h light-dark photoperiod. Plants were weekly fertilized with $5 \mathrm{~g}\left(\mathrm{NH}_{4}\right)_{2} \mathrm{SO}_{4}$ and $10 \mathrm{~g} \mathrm{FeSO}_{4} \cdot 7 \mathrm{H}_{2} \mathrm{O} / \mathrm{m}^{2}$. Forty-five-day-old plants were used for infection tests.

Rice plants were inoculated by the clipping method (Kauffman et al., 1973). Three to four leaves were used per plant and one leaf per rice line was clipped using $\mathrm{H}_{2} \mathrm{O}$ for control. Five to six plants were inoculated per isolate and were kept for $18 \mathrm{~h}$ in humid chambers ( $\geq 92 \%$ relative humidity) at $30 \pm 4^{\circ} \mathrm{C}$, and were thereafter brought back to greenhouse conditions for disease development. Fourteen days after inoculation, symptoms were evaluated by measuring the lesion length of the leaf covered by bacterial leaf blight lesion. Plants were divided into three classes: resistant, with lesion length of $0-3 \mathrm{~cm}$; intermediate, $3-9 \mathrm{~cm}$; and susceptible, $>9 \mathrm{~cm}$.

Rice cultivar IR24 was used to assess the virulence of $X_{0 o}$ strains KACC10331, BX043 and XKK.12 and their respective oryR mutants. Twenty to 25 leaves were infected by each of the six strains. Experiments were performed in triplicate. Lesion length data did not fulfil the requirements for ANovA and were statistically analysed in the program SPSS using the non-parametric tests: Kruskal-Wallis multiple comparison completed by the MannWhitney test.

\section{ACKNOWLEDGEMENTS}

S.F. is supported by an ICGEB fellowship. V.V.'s laboratory in the ICGEB Biosafety Outstation in Ca' Tron and J.B.'s ICGEB fellowship is also supported by the Fondazione Cassamarca, Treviso, Italy.

\section{REFERENCES}

Ahmer, B.M. (2004) Cell-to-cell signalling in Escherichia coli and Salmonella enterica. Mol Microbiol. 52, 933-945.

Alexeyev, M.F. (1999) The pKNOCK series of broad-host-range mobilizable suicide vectors for gene knockout and targeted DNA insertion into the chromosome of gram-negative bacteria. Biotechniques, 26, 824-826, 828.

Barber, C.E., Tang, J.L., Feng, J.X., Pan, M.Q., Wilson, T.J., Slater, H., Dow, J.M., Williams, P. and Daniels, M.J. (1997) A novel regulatory system required for pathogenicity of Xanthomonas campestris is mediated by a small diffusible signal molecule. Mol. Microbiol. 24, 555-566.

Better, M., Lewis, B., Corbin, D., Ditta, G. and Helinski, D.R. (1983) Structural relationships among Rhizobium meliloti symbiotic promoters. Cell, 35, 479-485.

Birnboim, H.C. (1983) A rapid alkaline extraction method for the isolation of plasmid DNA. Methods Enzymol. 100, 243-255.

Camara, M., Williams, P. and Hardman, A. (2002) Controlling infection by tuning in and turning down the volume of bacterial small-talk. Lancet Infect Dis. 2, 667-676.
Camilli, A. and Bassler, B.L. (2006) Bacterial small-molecule signaling pathways. Science, 311, 1113-1116.

Chai, Y. and Winans, S.C. (2004) Site-directed mutagenesis of a LuxR-type quorum-sensing transcription factor: alteration of autoinducer specificity. Mol. Microbiol. 51, 765-776.

Chatterjee, S. and Sonti, R.V. (2002) rpfF mutants of Xanthomonas oryzae pv. oryzae are deficient for virulence and growth under low iron conditions. Mol. Plant-Microbe Interact. 15, 463-471.

Collins, C.H., Arnold, F.H. and Leadbetter, J.R. (2005) Directed evolution of Vibrio fischeri LuxR for increased sensitivity to a broad spectrum of acyl-homoserine lactones. Mol. Microbiol. 55, 712-723.

Degrassi, G., Devescovi, G., Solis, R., Steindler, L. and Venturi, V. (2007) Oryza sativa rice plants contain molecules which activate different quorum sensing $\mathrm{N}$-acyl homoserine lactone biosensors and are sensitive to the specific AiiA lactonase. FEMS Microbiol Lett. 269, 213-220.

Dow, J.M., Crossman, L., Findlay, K., He, Y.Q., Feng, J.X. and Tang, J.L. (2003) Biofilm dispersal in Xanthomonas campestris is controlled by cellcell signaling and is required for full virulence to plants. Proc. Natl Acad. Sci. USA, 100, 10995-11000.

Fuqua, C. (2006) The QscR quorum-sensing regulon of Pseudomonas aeruginosa: an orphan claims its identity. J. Bacteriol. 188, 3169-3171.

Fuqua, C. and Greenberg, E.P. (2002) Listening in on bacteria: acylhomoserine lactone signalling. Nat. Rev. Mol. Cell Biol. 3, 685-695.

Fuqua, W.C., Winans, S.C. and Greenberg, E.P. (1994) Quorum sensing in bacteria: the LuxR-Luxl family of cell density-responsive transcriptional regulators. J. Bacteriol. 176, 269-275.

Goel, A.K., Rajagopal, L., Nagesh, N. and Sonti, R.V. (2002) Genetic locus encoding functions involved in biosynthesis and outer membrane localization of xanthomonadin in Xanthomonas oryzae pv. oryzae. J. Bacteriol. 184, 3539-3548.

He, Y.W., Wang, C., Zhou, L., Song, H., Dow, J.M. and Zhang, L.H. (2006) Dual signaling functions of the hybrid sensor kinase RpfC of Xanthomonas campestris involve either phosphorelay or receiver domain-protein interaction. J. Biol. Chem. 281, 33414-33421.

Hoang, H.H., Becker, A. and Gonzalez, J.E. (2004) The LuxR homolog ExpR, in combination with the Sin quorum sensing system, plays a central role in Sinorhizobium meliloti gene expression. J. Bacteriol. 186, 5460-5472.

Hwang, I., Li, P.L., Zhang, L., Piper, K.R., Cook, D.M., Tate, M.E. and Farrand, S.K. (1994) Tral, a Luxl homologue, is responsible for production of conjugation factor, the $\mathrm{Ti}$ plasmid $\mathrm{N}$-acylhomoserine lactone autoinducer. Proc. Natl Acad. Sci. USA, 91, 4639-4643.

Jha, G., Rajeshwari, R. and Sonti, R.V. (2007) Functional interplay between two Xanthomonas oryzae pv. oryzae secretion systems in modulating virulence on rice. Mol. Plant-Microbe Interact. 20, 31-40.

Kauffman, H.E., Reddy, A.P.K., Hsieh, S.P.Y. and Merca, S.D. (1973) An improved technique for evaluation of resistance rice varieties to Xanthomonas oryzae. Plant Dis. Rep. 57, 537-541.

Leach, J.E., Vera Cruz, C.M., Bai, J. and Leung, H. (2001) Pathogen fitness penalty as a predictor of durability of disease resistance genes. Annu. Rev. Phytopathol. 39, 187-224.

Leach, J.E. and White, F.F. (1996) Bacterial avirulence genes. Annu. Rev. Phytopathol. 34, 153-179.

Lee, B.M., Park, Y.J., Park, D.S., Kang, H.W., Kim, J.G., Song, E.S., Park, I.C., Yoon, U.H., Hahn, J.H., Koo, B.S., Lee, G.B., Kim, H., Park, H.S., Yoon, K.O., Kim, J.H., Jung, G.H., Koh, N.H., Seo, J.S., Go, S.J. (2005) The genome sequence of Xanthomonas oryzae pathovar oryzae KACC10331, the bacterial blight pathogen of rice. Nucleic Acids Res. 33, 577-586. 
Lequette, Y., Lee, J.H., Ledgham, F., Lazdunski, A. and Greenberg, E.P. (2006) A distinct QscR regulon in the Pseudomonas aeruginosa quorumsensing circuit. J. Bacteriol. 188, 3365-3370.

Milton, D.L., Chalker, V.J., Kirke, D., Hardman, A., Camara, M. and Williams, P. (2001) The LuxM homologue VanM from Vibrio anguillarum directs the synthesis of $\mathrm{N}$-(3-hydroxyhexanoyl) homoserine lactone and $\mathrm{N}$-hexanoylhomoserine lactone. J. Bacteriol. 183, 3537-3547.

Ochiai, H., Inoue, Y., Takeya, M., Sasaki, A. and Kaku, H. (2005) Genome sequence of Xanthomonas oryzae pv. oryzae suggests contribution of large numbers of effector genes and insertion sequences to its race diversity. Jpn Agric. Res. Q, 39, 275-287.

Qi, Z. and Mew, T.W. (1985) Adult-plant resistance of rice cultivars to bacterial blight. Plant Dis, 69, 896-898.

Sambrook, J., Fritsch, E.F. and Maniatis, T. (1989) Molecular Cloning: a Laboratory Manual, 2nd edn. Cold Spring Harbor, NY: Cold Spring Harbor Laboratory Press.

Schuster, M., Urbanowski, M.L. and Greenberg, E.P. (2004) Promoter specificity in Pseudomonas aeruginosa quorum sensing revealed by DNA binding of purified LasR. Proc. Natl Acad. Sci. USA, 101, 1583315839.

Shen, Y. and Ronald, P. (2002) Molecular determinants of disease and resistance in interactions of Xanthomonas oryzae pv. oryzae and rice. Microbes Infect. 4, 1361-1367.

Shiner, E.K., Rumbaugh, K.P. and Williams, S.C. (2005) Inter-kingdom signaling: deciphering the language of acyl homoserine lactones. FEMS Microbiol. Rev. 29, 935-947.

Sidhu, G.S. and Khush, G.S. (1978) Dominance of reversal of a bacterial blight resistance gene in some rice cultivars. Phytopathology, 68 , 461-463.

Steindler, L. and Venturi, V. (2007) Detection of quorum-sensing $\mathrm{N}$-acyl homoserine lactone signal molecules by bacterial biosensors. FEMS Microbiol. Lett. 266, 1-9.

Swings, J., van den Mooter, M., Vauterin, L., Hoste, B., Gillis, M., Mew, T.W. and Kersters, K. (1990) Reclassification of causal agents of bacterial blight (Xanthomonas campestris pv. oryzae) and bacterial leaf streak (Xanthomonas campestris (pv. oryzicola) of rice as pathovars of Xanthomonas oryzae (ex Ishiyama 1922) sp. nov., nom. rev. Int. J. Syst Bacteriol. 40, 309-311.

Tsuchiya, K., Mew, T.W. and Wakimoto, S. (1982) Bacteriological and pathological characteristics of wild-type and induced mutants of Xanthomonas campestris pv. oryzae. Phytopathology, 72, 43-46.

Urbanowski, M.L., Lostroh, C.P. and Greenberg, E.P. (2004) Reversible acyl-homoserine lactone binding to purified Vibrio fischeri LuxR protein. J. Bacteriol. 186, 631-637.

Vandamme, P., Pot, B., Gillis, M., de Vos, P., Kersters, K. and Swings, J. (1996) Polyphasic taxonomy, a consensus approach to bacterial systematics. Microbiol. Rev. 60, 407-438.

Walters, M. and Sperandio, V. (2006) Quorum sensing in Escherichia coli and Salmonella. Int. J. Med. Microbiol. 296, 125-131.

Waters, C.M. and Bassler, B.L. (2005) Quorum sensing: cell-to-cell communication in bacteria. Annu. Rev. Cell Dev. Biol. 21, 319-346.

Zhu, J. and Winans, S.C. (2001) The quorum-sensing transcriptional regulator TraR requires its cognate signaling ligand for protein folding, protease resistance, and dimerization. Proc. Natl Acad. Sci. USA, 98, 1507-1512. 